\title{
Bemerkung zu dem Aufsatze von Schneller „Beiträge zur Theorie des Sehielens".
}

Von

Dr. Carl Hess.

In seinen "Beiträgen zur Theorie des Schielens" vertheidigt Schneller die von ihm schon früher vertretene Ansicht, dass oine ungleiche Accommodation beider Augen möglich sei, mit den folgenden Worten:

„Das hauptsächlichste Argument dafür (nämlich das Vorkommen einer ungleichen Accommodation) liegt in folgender Beobachtung, die ich damals machte und mittheilte. Sah ich nach kleinster, (eben erkennbarer) Schrift (z. B. Jäg. 1) in bestimmter Entfernung, dann konnte ich vor das eine Auge + oder - Gläser bis zu bestimmter Stärke bringen, ohne dass die Schrift undeutlich wurde, während, wenn die Gläser eine bestimmte Stärke ( $+1,25$ bis 2,0 war es damals) überschritten, die Objecte, die kleinen Buchstaben Ränder bekamen und behielten. Bei den Gläsern, die dem Deutlichsehen mit beiden Augen keinen Eintrag thaten, dauerte es immer eine bestimmte Zeit, ehe dieses Klarsehen eintrat, das zu Anfang fehlte, auch war es mit einem Gefühl des $Z$ wanges in einem oder beiden Augen verbunden. Nahm ich dann das Glas vom Auge fort, so sah ich zu Anfang wieder Ränder oder Schatten um die Buchstaben, die sich in merklicher Zeit und mit allmälig weichendem Gefühl des Unbehagens in den Augen verloren. Gerade diese Zeit, die beim Vorsetzen und Wegnehmen der Gläser verging, bis Deutlichsehen der sehr feinen objecte eintrat und das Gefuhl des Zwanges oder Unbehagens in den Augen 
Bemerkung zu Schneller's „Beitr. zur Theorie des Schielens". 259

scheinen mir dafürr zu sprechen, dass es sich wirklich um eine Verschiedenheit in der Accommodation handelt."

Es lässt sich leicht zeigen, dass auch bei dem von Schneller beschriebenen Versuche eine ungleiche Accommodation nicht eintritt und dass ,das Gefuhl des Unbehagens" andere Ursachen gehabt haben muss. Man halte bei dem Schneller'schen Versuche eine möglichst feine Nadel so zwischen Kopf und Papierfäche in der Medianebene, dass die Spitze der Nadel sich etwa $1 \mathrm{~cm}$ über der Ebene des Papieres befindet und in der Richtung der zu lesenden Worte gesehen wird. Die Nadel erscheint jetzt, beim Lesen der Worte, in nahe boi einander gelegenen Doppelbildern. Zugleich erscheint die Schrift, bei einer künstlichen Refractionsdifferenz von $1,0 \mathrm{D}$ ganz deutlich. Schneller schliesst daraus, dass beide Augen auf die gelesene Stelle accommodirt sein müssten. Wäre dies der Fall, so müssten die beiden Doppelbilder der Nadelspitze ganz gleich erscheinen. Dies ist aber niemals der Fall; vielmehr erscheinen, auch wenn die Refractionsdifferenz $1,0 \mathrm{D}$ nicht übersteigt, stets die beiden Doppelbilder ungleich, das eine nahezu vollständig scharf, das andere in Zerstreuungskreisen, deren Grösse mit der Refractionsdifferenz wächst. Für den Ausfall des Versuches ist es gleichgïltig, ob man die Nadel gleich anfangs vor die Schrift gebracht hat, oder erst nach längerem Lesen, sodass die Augen Zeit genug gehabt hätten, sich ungleich zu accommodiren. Darin liegt der schlagende Beweis, dass eine ungleiche Accommodation nicht stattgefunden hat.

Dass die Schrift auch dann dentlich erscheint, wenn nur ein Auge scharfe Netzhautbilder erhält, hat seinen Grund darin, dass diese scharf umrissenen Netzhautbilder nach den bekannten Gesetzen des Wettstreites der Sehfelder die mehr verschwommenen Bilder des anderen Auges „besiegen“, was nicht ausschliesst, dass unter Umständen auch diese letzteren vorübergehend bemerklich werden kön- 
260 O. Hess, Bem zu Schnellex's „Beitr. z. Theorie d. Schielens". nen. Auch kann man bei dem Versuche sehr wohl das Gefühl einer Störung des gewöhnlichen Sehens haben, ungefähr so, wie beim. Sehen dureh eine Brille, deren eines Glas etwa angelaufen oder durch Berühren mit den fettigen Wimpern getrübt ist. Vielleicht findet hierin das Gefühl des Unbehagens, welches Schneller bei den Versuchen hatte, wenigstens theilweise seine Erklärung. 